\title{
Experimental Diffusion Research on BCC Ti-Al-Sn Ternary Alloys
}

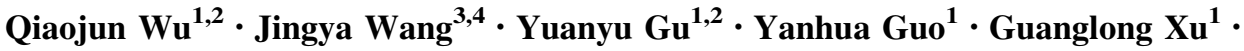 \\ Yuwen $\mathrm{Cui}^{1,2}$
}

Submitted: 30 April 2018/in revised form: 15 June 2018/Published online: 27 August 2018

(C) ASM International 2018

\begin{abstract}
The interdiffusion behavior of BCC alloys of TiSn binary and Ti-Al-Sn ternary was investigated at $1473 \mathrm{~K}$ $\left(1200{ }^{\circ} \mathrm{C}\right)$ by the diffusion-couple technique. The extracted interdiffusion coefficients of Ti-Sn binary was found to gradually increase with increasing the Sn content, whereas those of Ti-Al-Sn ternary, either main or cross, greatly enhance as the content of diffusing species increases. By a way of comparison, Sn diffusion in Ti-Al-Sn ternary was discerned to occur by the vacancy mechanism.
\end{abstract}

Keywords BCC Ti-Al-Sn alloys · diffusion couple · impurity diffusion · interdiffusion behavior

This invited article is part of a special issue of the Journal of Phase Equilibria and Diffusion in honor of Prof. Zhanpeng Jin's 80th birthday. The special issue was organized by Prof. Ji-Cheng (JC) Zhao, The Ohio State University; Dr. Qing Chen, Thermo-Calc Software AB; and Prof. Yong Du, Central South University.

\section{Guanglong Xu}

guanglongxu@njtech.edu.cn

$\triangle$ Yuwen Cui

ycui@unizar.es

1 Tech Institute of Advanced Materials and School of Materials Science and Engineering, Nanjing Tech University, Nanjing 210009, People's Republic of China

2 Instituto de Ciencia de Materiales de Aragon, Zaragoza 50009, Spain

3 Department of Materials Science, Polytechnic University of Madrid, 28040 Madrid, Spain

4 IMDEA Materials Institute, C/Eric Kandel 2, Getafe, 28906 Madrid, Spain

\section{Introduction}

Titanium and titanium alloys are excellent materials for aerospace applications owing to their high strength-todensity, higher yield strength, good corrosion resistance and high-temperature resistance. ${ }^{[1]}$ The main application of titanium alloy in the aerospace industry is high-temperature titanium alloy used at temperatures not higher than $900 \mathrm{~K}$ $\left(627^{\circ} \mathrm{C}\right)$. Many of typical high-temperature titanium alloys that have been applied as compressor disks and blades of gas turbines for advanced jet engines, e.g. IMI834, ${ }^{[2]} \mathrm{Ti}$ $1100,{ }^{[3]} \mathrm{BT} 36,{ }^{[4]}$ and Ti600, ${ }^{[5]}$ have common elements like $\mathrm{Al}$ and $\mathrm{Sn}$ and others. The practical $\alpha$-stabilizing element of $\mathrm{Al}$ increases tensile strength and creep resistance while reducing alloy density, ${ }^{[6]}$ and the neutral element $\mathrm{Sn}$ is used as solid-solution strengthening element, often in conjunction with $\mathrm{Al}$ to achieve higher strength without embrittlement. ${ }^{[7]}$ Sn can be also considered as the $\alpha$-stabilizing element because it can replace $\mathrm{Al}$ in the hexagonal ordered $\mathrm{Ti}_{3} \mathrm{Al}$ phase $\left(\alpha_{2}\right){ }^{[8]}$

The microstructures and mechanical properties, such as strength, ductility, creep resistance and fracture toughness, of high-temperature titanium alloys, are markedly affected by thermomechanical treatment and aging via such complex processes as recovery, recrystallization, grain size growth, phase transformation, and precipitation, which are all related to diffusion and its interaction. Diffusion of some $\beta$-stabilizing elements in binary and ternary Ti-based alloys in BCC region have been performed previously, including $\mathrm{Ti}-\mathrm{Al}-\mathrm{Cr},{ }^{[9]} \mathrm{Ti}-\mathrm{Al}-\mathrm{V},{ }^{[10]} \mathrm{Ti}-\mathrm{Al}-\mathrm{Co},{ }^{[1]} \mathrm{Ti}-\mathrm{Al}-$ $\mathrm{Fe}^{\left[{ }^{[12]}\right.} \mathrm{Ti}-\mathrm{Al}-\mathrm{Mo},{ }^{[13]}$ and Ti-Al-Ni. ${ }^{[14]}$ Diffusion of $\mathrm{Sn}$ in BCC-Ti and Ti-Sn alloys have been researched, ${ }^{[15-20]}$ however, that in BCC Ti-Al-Sn ternary alloys have not been addressed. Accordingly, the objectives of this work are to determine the diffusion properties of $\mathrm{BCC}$ Ti-Sn 
binary and Ti-Al-Sn ternary, and by a way of comparison to unveil diffusion mechanism of $\mathrm{Sn}$ in titanium alloys.

\section{Experimental Procedure}

\subsection{Diffusion Couples and Composition Profiles}

Nine ingots including seven binary and two ternary alloys were prepared with pure metals of 99.9 mass $\%$ sponge $\mathrm{Ti}$, 99.99 mass \% $\mathrm{Al}$ and the master alloy of $\mathrm{Ti}-75 \% \mathrm{Sn}$ (mass percent) by levitation melting in the argon atmosphere. As listed in Table 1, the nominal and actual compositions of Ti-Al, Ti-Sn binary and Ti-Al-Sn ternary alloys all locate in $\mathrm{BCC}$ region at $1473 \mathrm{~K}\left(1200{ }^{\circ} \mathrm{C}\right)$, according to the accepted $\mathrm{Ti}-\mathrm{Al},{ }^{[21]} \mathrm{Ti}-\mathrm{Sn},{ }^{[22]}$ and $\mathrm{Ti}-\mathrm{Al}-\mathrm{Sn}^{[23]}$ phase diagrams. The samples were re-melted six times to attain a homogeneous composition, and then solid-solutioned at $1473 \mathrm{~K}\left(1200{ }^{\circ} \mathrm{C}\right)$ for $18 \mathrm{~h}$ under vacuum, finally followed by water quenching. This results in the average grain size of the ingots larger than several millimeters so that the grain boundary diffusion effect can be negligible. The ingots were cut into small cylinder samples of $\varphi 15 \times 5 \mathrm{~mm}$ in size by wire-electrode cutting. The surfaces of alloy disks were polished by the standard metallographic techniques to obtain the mirror-like surface. All the diffusion couples were assembled with appropriate pairs of the small disks under vacuum at $1173 \mathrm{~K}\left(900{ }^{\circ} \mathrm{C}\right)$ for $90 \mathrm{~min}$ with a load of $10 \mathrm{MPa}$ on a vacuum diffusion bonding machine. The diffusion couples were sealed into quartz capsules with argon as shield gas and finally annealed at $1473 \mathrm{~K}\left(1200^{\circ} \mathrm{C}\right)$ for $10 \mathrm{~h}$ followed by water quenching.

After diffusion treatment, the samples were cut to parallel to the diffusion direction, and the cut surface was polished by standard metallographic techniques. The composition profiles were analytically measured by electron microprobe analysis (EPMA) on JEOL JXA 8230.

\subsection{Extraction of Diffusion Coefficients}

To avoid the errors in determining the so-called Matano interface, the Sauer-Friese method ${ }^{[24]}$ was accepted to extract the binary interdiffusion coefficient with a composition dependence. It introduces a relative composition variable, namely $Y=\frac{x-x_{L}}{x_{R}-x_{L}}\left(x_{L}\right.$ and $x_{R}$ represent the compositions at the far left and far right ends, respectively), to solve inverse composition profiles of binary system. As such, a binary interdiffusion coefficient can be yielded via Eq 1.

$\tilde{D}\left(Y^{*}\right)=\frac{V_{m}}{2 t(d Y / d z)_{Z^{*}}}\left[\left(1-Y^{*}\right) \int_{-\infty}^{Z^{*}} \frac{Y}{V_{m}} d z+Y^{*} \int_{Z^{*}}^{+\infty} \frac{1-Y}{V_{m}} d z\right]$,

(Eq1)

where $V_{m}$ is the molar volume; $t$ is the diffusion time and $z$ denotes diffusion distance. Due to the lack of experimental data of the variation of $V_{m}$ with the composition, it is regarded as a constant of $1 \mathrm{E}-5 \mathrm{~m}^{3} / \mathrm{mol}$ during the interdiffusion coefficients calculations. Errors introduced by the neglect of molar volume change are considered to be well within the analytical error and may therefore be ignored. ${ }^{\text {[25] }}$

By introducing a set of similar normalized composition variables, Whittle and Green ${ }^{[26]}$ devised a scheme to extract the interdiffusion coefficients of ternary systems using a pair diffusion couples whose diffusion paths have an intersection composition. For the Ti-Al-Sn ternary system with $\mathrm{Ti}$ as the solvent, it yields $\mathrm{Eq} 2$ :

$$
\begin{aligned}
& \frac{1}{2 t}\left(\frac{\partial z}{\partial Y_{\mathrm{Al}}}\right)_{Z^{*}}\left[\left(1-Y_{\mathrm{Al}}\right) \int_{-\infty}^{Z^{*}} Y_{\mathrm{Al}} d z+Y_{\mathrm{Al}} \int_{Z^{*}}^{+\infty}\left(1-Y_{\mathrm{Al}}\right) d z\right] \\
& \quad=\tilde{D}_{\mathrm{AlAl}}^{\mathrm{Ti}}+\tilde{D}_{\mathrm{AlSn}}^{\mathrm{Ti}} \frac{\partial x_{\mathrm{Sn}}}{\partial x_{\mathrm{Al}}}
\end{aligned}
$$

(Eq 2a)
Table 1 Terminal Compositions of Ti-Sn binary and Ti-Al-Sn Ternary Diffusion Couples

\begin{tabular}{lll}
\hline Couple name & Nominal composition, at.\% & Actual compositions, at.\% \\
\hline G1 & Ti/ Ti-9Al-5.5Sn & Ti/Ti-9.4Al-5.3Sn \\
G2 & Ti/Ti-14Al-3.5Sn & Ti/Ti-14.4Al-3.6Sn \\
G3 & Ti-9.0Al-5.5Sn/Ti-15.0Al & Ti-8.5Al-5.6Sn/Ti-14.7Al \\
H1 & Ti-2.5Sn/Ti-5.0Al & Ti-2.6Sn/Ti-5.4Al \\
H2 & Ti-5.5Sn/Ti-5.0Al & Ti-5.6Sn/Ti-5.1Al \\
H3 & Ti-5.5Sn/Ti-15.0Al & Ti-5.5Sn/Ti-14.1Al \\
H4 & Ti-8.5Sn/Ti-10.0Al & Ti-8.3Sn/Ti-9.6Al \\
H5 & Ti-8.5Sn/Ti-15.0Al & Ti-8.6Sn/Ti-15.7Al \\
H6 & Ti-8.5Sn/Ti-20.0Al & Ti-8.3Sn/Ti-19.6Al \\
J1 & Ti/Ti-8.5Sn & Ti/Ti-8.5Sn \\
\hline
\end{tabular}




$$
\begin{aligned}
& \frac{1}{2 t}\left(\frac{\partial z}{\partial Y_{S n}}\right)_{Z^{*}}\left[\left(1-Y_{\mathrm{Sn}}\right) \int_{-\infty}^{Z^{*}} Y_{\mathrm{Sn}} d z+Y_{\mathrm{Sn}} \int_{Z^{*}}^{+\infty}\left(1-Y_{\mathrm{Sn}}\right) d z\right] \\
& \quad=\tilde{D}_{\mathrm{SnSn}}^{\mathrm{Ti}}+\tilde{D}_{\mathrm{SnAl}}^{\mathrm{Ti}} \frac{\partial x_{\mathrm{Al}}}{\partial x_{\mathrm{Sn}}}
\end{aligned}
$$

where $\tilde{D}_{\mathrm{AlAl}}^{\mathrm{Ti}}$ and $\tilde{D}_{\mathrm{SnSn}}^{\mathrm{Ti}}$ are the main interdiffusion coefficients; $\tilde{D}_{A l S n}^{T i}$ and $\tilde{D}_{\mathrm{SnAl}}^{\mathrm{Ti}}$ are the cross interdiffusion coefficients. Two main and two cross interdiffusion coefficients can be extracted by solving a homogeneous system of four linear equations at the cross composition of two independent diffusion profiles.

The impurity diffusivity, referring to the infinite dilution of solute diffusion coefficient in pure metal or a homogeneous binary alloy, was extracted by the Hall method ${ }^{[27,28]}$ for the Ti-Sn binary and by its generalized version for the Ti-Al-Sn ternary. ${ }^{[28]}$ It is in the methods that the composition profile is rewritten as $\mu=\operatorname{erf}^{-1}(2 Y-1)$ versus $\lambda=$ $x / \sqrt{t}$ and then fitted with a linear relation $\mu=h \lambda+k$. The impurity diffusivity for the left and right composition can be determined by Eq $3 \mathrm{a}$ and $3 \mathrm{~b}$, respectively,

$$
\begin{aligned}
& \tilde{D}\left(x^{\prime}\right)=\frac{1}{4 h_{1}^{2}}\left[1+2 k_{1} \pi^{1 / 2} \exp \left(\mu^{2}\right) \times Y\left(x^{\prime}\right)\right], \\
& \tilde{D}\left(x^{\prime}\right)=\frac{1}{4 h_{2}^{2}}\left\{1-2 k_{2} \pi^{1 / 2} \exp \left(\mu^{2}\right) \times\left[1-Y\left(x^{\prime}\right)\right]\right\},
\end{aligned}
$$

with the linear fit coefficients $h_{1}$ and $k_{1}$ for the left side, and $h_{2}$ and $k_{2}$ for the right side. Regarding the Ti-Al-Sn ternary, the impurity diffusivities of $\mathrm{Al}$ in $\mathrm{Ti}-\mathrm{Sn}$ and $\mathrm{Sn}$ in Ti-Al were computed from the profiles of diffusion couples H1$\mathrm{H} 6$ at the terminal compositions.

\section{Results and Discussion}

\subsection{Diffusion Paths and Interdiffusion Coefficients}

The composition profile measured in the diffusion zone is shown in Fig. 1(a) for the Ti/Ti-8.5 at.\% Sn binary couple and in Fig. 1(b) for the representative G2 and H6 Ti-Al-Sn ternary couples, all annealed at $1473 \mathrm{~K}\left(1200{ }^{\circ} \mathrm{C}\right)$ for $10 \mathrm{~h}$. The diffusion distances for all diffusion couples are typically around 2500 microns, which is significantly larger than that (by a rough estimate, a few microns) arising from the diffusion bonding at $1173 \mathrm{~K}\left(900{ }^{\circ} \mathrm{C}\right)$ for 90 mins. Note that the experimental EPMA profiles were represented by the error function expansion ${ }^{[29]}$ to provide the profiles in high-accuracy analytical form for the extraction of diffusion coefficients. It is in the inset of Fig. 1(a) that the extracted Ti-Sn binary interdiffusion coefficients by the Sauer-Friese method are displayed versus the content of
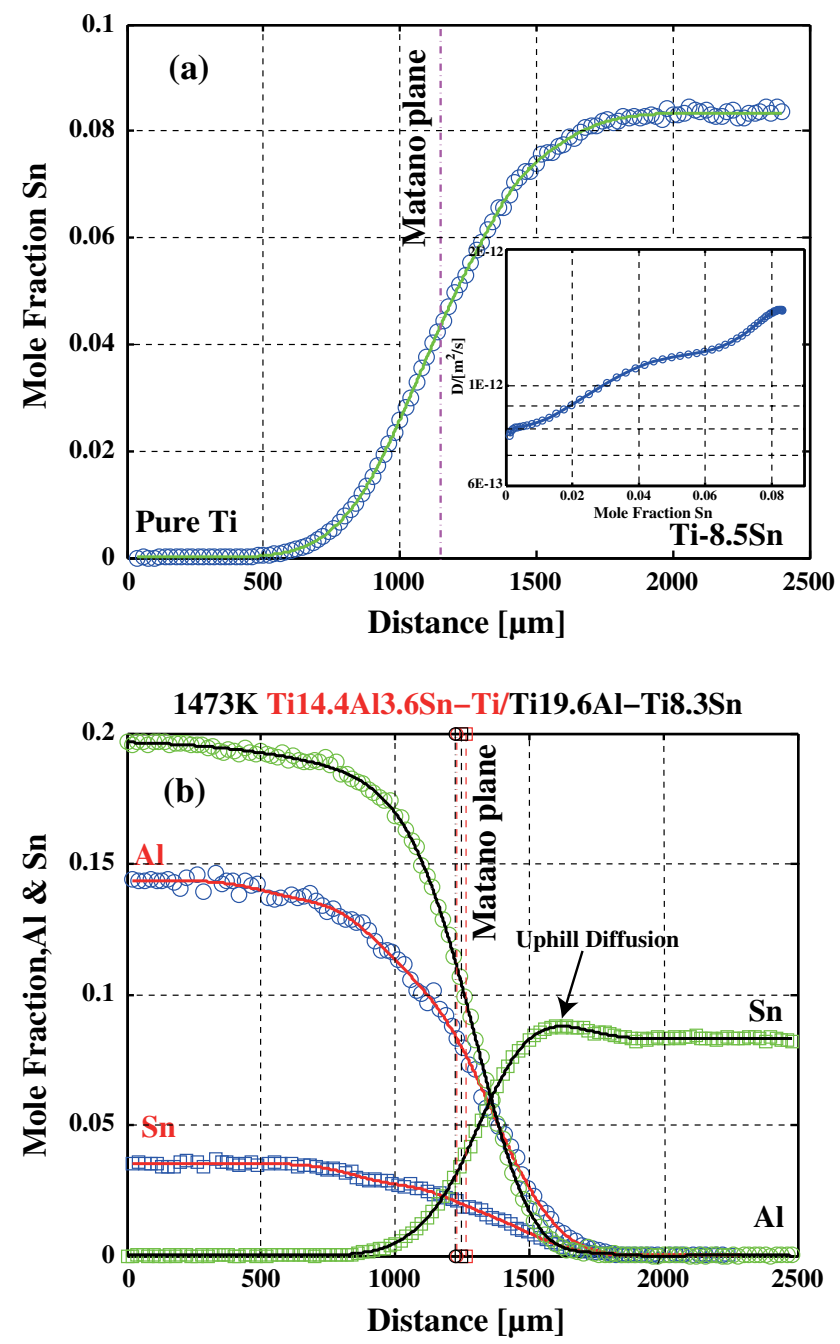

Fig. 1 The composition profiles, (a) the J1 Ti-Sn binary couple, (b) the G2-H6 Ti-Al-Sn ternary couples, annealed at $1473 \mathrm{~K}$ for $10 \mathrm{~h}$. The symbols are the EPMA data

Sn. As expected by an empirical supposition, ${ }^{[30]}$ the binary Ti-Sn diffusion rate is gradually enhanced by adding the $\mathrm{Sn}$ solute that has a lower melting temperature, in good accord with the previous studies. ${ }^{[18-20]}$

While it learns from the composition profiles of the ternary couples that the penetration depth of $\mathrm{Al}$, as wide as about $1-2 \mathrm{~mm}$, is comparable to that of $\mathrm{Sn}$, revealing that $\mathrm{Al}$ diffuses comparably to $\mathrm{Sn}$ in BCC Ti-Al-Sn system at $1473 \mathrm{~K}$. The fact is further justified by the diffusion paths obtained from all ternary diffusion couples at $1473 \mathrm{~K}$ $\left(1200^{\circ} \mathrm{C}\right)$ when plotted on the Ti-Al-Sn ternary isotherm in Fig. 2. As shown, all the paths are slightly S-shaped with a minor bent, suggesting a small difference between the diffusion rates for $\mathrm{Al}$ and $\mathrm{Sn}$ at $1473 \mathrm{~K}\left(1200{ }^{\circ} \mathrm{C}\right)$. The extracted ternary interdiffusion coefficients of the Ti-Al-Sn BCC alloys at $1473 \mathrm{~K}\left(1200{ }^{\circ} \mathrm{C}\right)$ are listed in Table 2, and our examinations show that they all satisfy the 
thermodynamic constraints. ${ }^{[31]}$ It can be seen that all the coefficients are positive and that the main coefficients $\tilde{D}_{\mathrm{AlAl}}^{\mathrm{Ti}}$ and $\tilde{D}_{\mathrm{SnSn}}^{\mathrm{Ti}}$ are indeed comparable for most of the compositions. The average values, summarized in Table 2, indicates that $\tilde{D}_{\mathrm{AlAl}}^{\mathrm{Ti}}\left(9.2 \mathrm{E}-13 \mathrm{~m}^{2} / \mathrm{s}\right)$ is approximately 1.5 times greater than $\tilde{D}_{\mathrm{AlSn}}^{\mathrm{Ti}}\left(5.9 \mathrm{E}-13 \mathrm{~m}^{2} / \mathrm{s}\right)$ while $\tilde{D}_{\mathrm{SnSn}}^{\mathrm{Ti}}\left(8.2 \mathrm{E}-13 \mathrm{~m}^{2} / \mathrm{s}\right)$ is about 3.5 times than $\tilde{D}_{\mathrm{SnAl}}^{\mathrm{Ti}}$

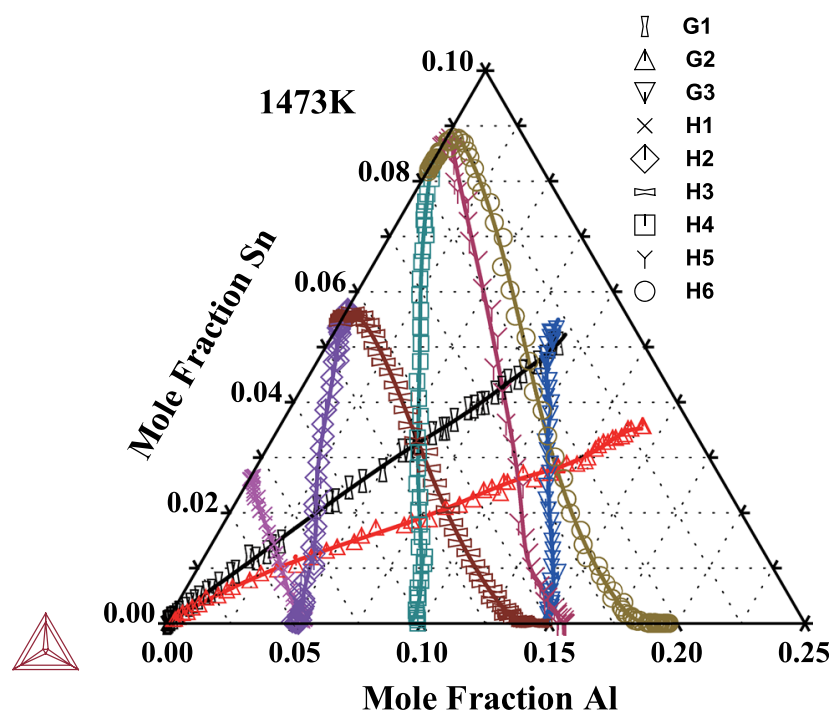

Fig. 2 Diffusion paths for all the Ti-Al-Sn ternary diffusion couples annealed at $1473 \mathrm{~K}$ for $10 \mathrm{~h}$ $\left(2.4 \mathrm{E}-13 \mathrm{~m}^{2} / \mathrm{s}\right)$, also revealing that diffusion of $\mathrm{Sn}$ is much more affected by $\mathrm{Al}$.

\subsection{Composition and Temperature Dependence of Diffusion Coefficients}

The impurity diffusivities of $\mathrm{Al}$ in Ti-Sn and $\mathrm{Sn}$ in Ti-Al binary alloys, i.e. $D_{\mathrm{Al}(\mathrm{Ti}-\mathrm{Sn})}^{*}$ and $D_{\mathrm{Sn}(\mathrm{Ti}-\mathrm{Al})}^{*}$ were determined from $\mathrm{Sn}$ and $\mathrm{Al}$ profiles at the terminal compositions in six ternary couples (H1-H6) by the generalized Hall's method, respectively. As listed in Table $3, \tilde{D}_{\mathrm{Al}(\mathrm{Ti}-\mathrm{Sn})}^{*}$ and $\tilde{D}_{\mathrm{Sn}(\mathrm{Ti}-\mathrm{Al})}^{*}$ decrease respect to adding $\mathrm{Sn}$ and $\mathrm{Al}$ contents respectively to the binary alloys. It is well known that, in i$\mathrm{j}-\mathrm{k}$ ternary, the interdiffusion coefficients satisfy three constraints in Eq 4, ${ }^{[32]}$

$\lim _{C_{j \rightarrow 0}} \tilde{D}_{i i}^{k}=\tilde{D}_{i k}^{\text {binary }}$

$\lim _{C_{i \rightarrow 0}} D_{i i}^{k}=\tilde{D}_{i}^{i k^{*}}$

$\lim _{C_{i} \rightarrow 0} \tilde{D}_{i j}^{k}=0$

stating that the limits of $\tilde{D}_{i i}^{k}$ and $\tilde{D}_{i j}^{k}$ in the vicinity of the binary are retarded to binary interdiffusion coefficient or the impurity of the third element in binary alloy or zero. Together with the binary $\left(\tilde{D}_{\mathrm{Ti}-\mathrm{Al}}\right.$ from Ref 33 and $\tilde{D}_{\mathrm{Ti}-\mathrm{Sn}}$ from this work) and ternary interdiffusion coefficients have

Table 2 Interdiffusion coefficients in BCC Ti-Al-Sn Alloys at $1473 \mathrm{~K}$

\begin{tabular}{|c|c|c|c|c|c|c|c|c|c|c|}
\hline \multirow[t]{2}{*}{ Diffusion couples } & \multicolumn{2}{|c|}{ Composition, at. $\%$} & \multicolumn{4}{|c|}{ Interdiffusion coefficients, $10^{-13} \mathrm{~m}^{2} / \mathrm{s}$} & \multicolumn{4}{|c|}{ Position of Matano plane, $\mu \mathrm{m}$} \\
\hline & $\mathrm{Al}$ & Sn & $\tilde{D}_{\mathrm{AlAl}}^{\mathrm{Ti}}$ & $\tilde{D}_{\mathrm{AlSn}}^{\mathrm{Ti}}$ & $\tilde{D}_{\mathrm{SnSn}}^{\mathrm{Ti}}$ & $\tilde{D}_{\text {SnAl }}^{\mathrm{Ti}}$ & G-Al & G-Sn & $\mathrm{H}-\mathrm{Al}$ & $\mathrm{H}-\mathrm{Sn}$ \\
\hline G1-H1 & 2.4 & 1.4 & 6.3 & 0.8 & 6.5 & 0.5 & 1236 & 1251 & 1292 & 1278 \\
\hline G1-H2 & 3.4 & 2.0 & 5.5 & 1.9 & 6.9 & 0.3 & 1236 & 1251 & 1242 & 1243 \\
\hline G1-H3 & 5.8 & 3.3 & 8.2 & 4.6 & 9.0 & 2.8 & 1236 & 1251 & 1261 & 1256 \\
\hline G1-H4 & 5.8 & 3.3 & 8.3 & 4.4 & 9.3 & 2.7 & 1236 & 1251 & 1257 & 1259 \\
\hline G1-H5 & 7.8 & 4.3 & 8.1 & 5.0 & 9.2 & 3.1 & 1236 & 1251 & 1238 & 1242 \\
\hline G1-H6 & 8.5 & 4.7 & 7.3 & 3.5 & 9.6 & 3.2 & 1236 & 1251 & 1223 & 1261 \\
\hline G2-H1 & 3.2 & 1.0 & 7.3 & 1.8 & 7.2 & 0.7 & 1232 & 1263 & 1292 & 1278 \\
\hline G2-H2 & 4.2 & 1.2 & 7.9 & 2.0 & 7.3 & 0.9 & 1232 & 1263 & 1241 & 1243 \\
\hline G2-H3 & 8.3 & 2.1 & 11.1 & 8.2 & 7.4 & 1.5 & 1232 & 1263 & 1261 & 1256 \\
\hline G2-H4 & 7.6 & 1.9 & 9.9 & 7.5 & 8.1 & 1.2 & 1232 & 1263 & 1257 & 1259 \\
\hline G2-H5 & 10.5 & 2.6 & 15.0 & 14.0 & 8.3 & 2.8 & 1232 & 1263 & 1238 & 1242 \\
\hline G2-H6 & 11.8 & 2.8 & 14.5 & 14.0 & 8.3 & 2.8 & 1232 & 1263 & 1223 & 1261 \\
\hline G3-G2 & 11.5 & 2.8 & 15.5 & 13.5 & 9.8 & 2.9 & 1242 & 1242 & 1232 & 1263 \\
\hline G3-H5 & 14.5 & 0.4 & 8.4 & 4.4 & 7.3 & 0.8 & 1242 & 1242 & 1238 & 1242 \\
\hline G3-H6 & 10.6 & 3.5 & 8.6 & 4.9 & 7.1 & 2.2 & 1242 & 1242 & 1223 & 1261 \\
\hline H3-H4 & 5.8 & 3.3 & 8.2 & 4.2 & 10.1 & 3.3 & 1261 & 1256 & 1257 & 1259 \\
\hline H6 (a) & 0.5 & 8.8 & 5.3 & & & 8.8 & & & & \\
\hline Average & 7.2 & 2.9 & 9.2 & 5.9 & 8.2 & 2.4 & & & & \\
\hline
\end{tabular}

(a) "Darken-type" couple ${ }^{[34]}$ local maximum of Sn 
Table 3 Impurity coefficients of $\mathrm{Al}$ in $\mathrm{Ti}-\mathrm{Sn}$ and $\mathrm{Sn}$ in $\mathrm{Ti}-\mathrm{Al}$ Binary Alloys at $1473 \mathrm{~K}$

\begin{tabular}{lclc}
\hline Composition & Impurity diffusivity, $\mathrm{m}^{2} / \mathrm{s}$ & Composition & Impurity diffusivity, ${ }^{2} / \mathrm{s}$ \\
\hline$\tilde{D}_{\mathrm{Al}(\mathrm{Ti}-0 \mathrm{Sn})}^{*}$ & $5.8 \times 10^{-13[33]}$ & $\tilde{D}_{\mathrm{Sn}(\mathrm{Ti}-0 \mathrm{Al})}^{*}$ & $6.4 \times 10^{-13[18]}$ \\
$\tilde{D}_{\mathrm{Al}(\mathrm{Ti}-2.6 \mathrm{Sn})}^{*}$ & $5.2 \times 10^{-13}$ & $\tilde{D}_{\mathrm{Sn}(\mathrm{Ti}-5.1 \mathrm{Al})}^{*}$ & $5.9 \times 10^{-13}$ \\
$\tilde{D}_{\mathrm{Al}(\mathrm{Ti}-5.5 \mathrm{Sn})}^{*}$ & $3.7 \times 10^{-13}$ & $\tilde{D}_{\mathrm{Sn}(\mathrm{Ti}-9.6 \mathrm{Al})}^{*}$ & $5.6 \times 10^{-13}$ \\
$\tilde{D}_{\mathrm{Al}(\mathrm{Ti}-8.6 \mathrm{Sn})}^{*}$ & $2.8 \times 10^{-13}$ & $\tilde{D}_{\mathrm{Sn}(\mathrm{Ti}-15.7 \mathrm{Al})}^{*}$ & $4.6 \times 10^{-13}$ \\
& & $\tilde{D}_{\mathrm{Sn}(\mathrm{Ti}-19.6 \mathrm{Al})}$ & $2.5 \times 10^{-13}$ \\
\hline
\end{tabular}
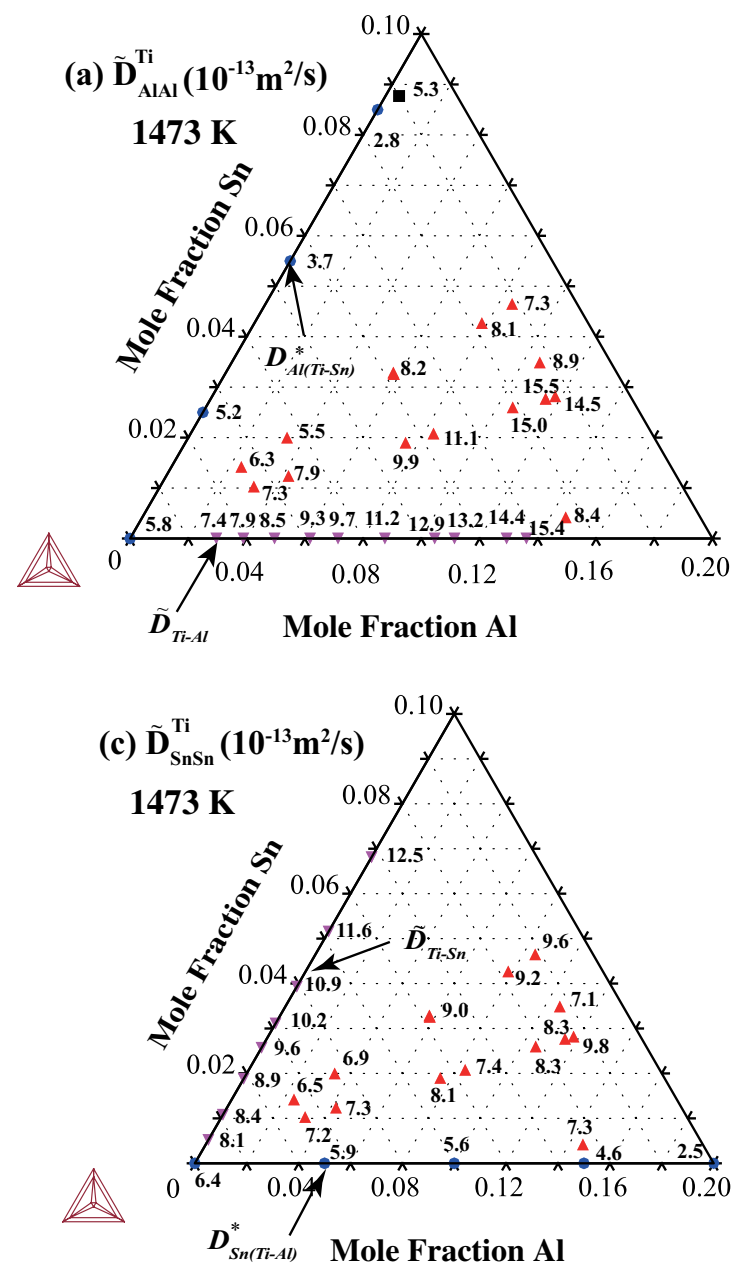

Fig. 3 The main and cross interdiffusion coefficients of the Ti-Al-Sn BCC ternary alloys at $1473 \mathrm{~K}$ (a) $\tilde{D}_{\mathrm{AlAl}}^{\mathrm{Ti}}$; (b) $\tilde{D}_{\mathrm{AlSn}}^{\mathrm{Ti}}$; (c) $\tilde{D}_{\mathrm{SnSn}}^{\mathrm{Ti}}$; and (d) $\tilde{D}_{\mathrm{SnAl}}^{\mathrm{Ti}}$, together with the impurity diffusion coefficients $\tilde{D}_{\mathrm{Sn}(\mathrm{Ti}-\mathrm{Al})}^{*}$

come the mapping of all diffusion rates on the Ti-Al-Sn ternary isotherm in Fig. 3. It is apparent that the main interdiffusion term of the Ti-Al-Sn ternary, either $\tilde{D}_{\mathrm{AlAl}}^{E}$ or $\tilde{D}_{\mathrm{SnSn}}^{\mathrm{Ti}}$, profoundly enhances as the content of diffusing species increases while weakly depends on that of the others, and this more or less holds for the two cross terms as well. Close inspection of the variations of ternary coefficients versus the composition of diffusing species
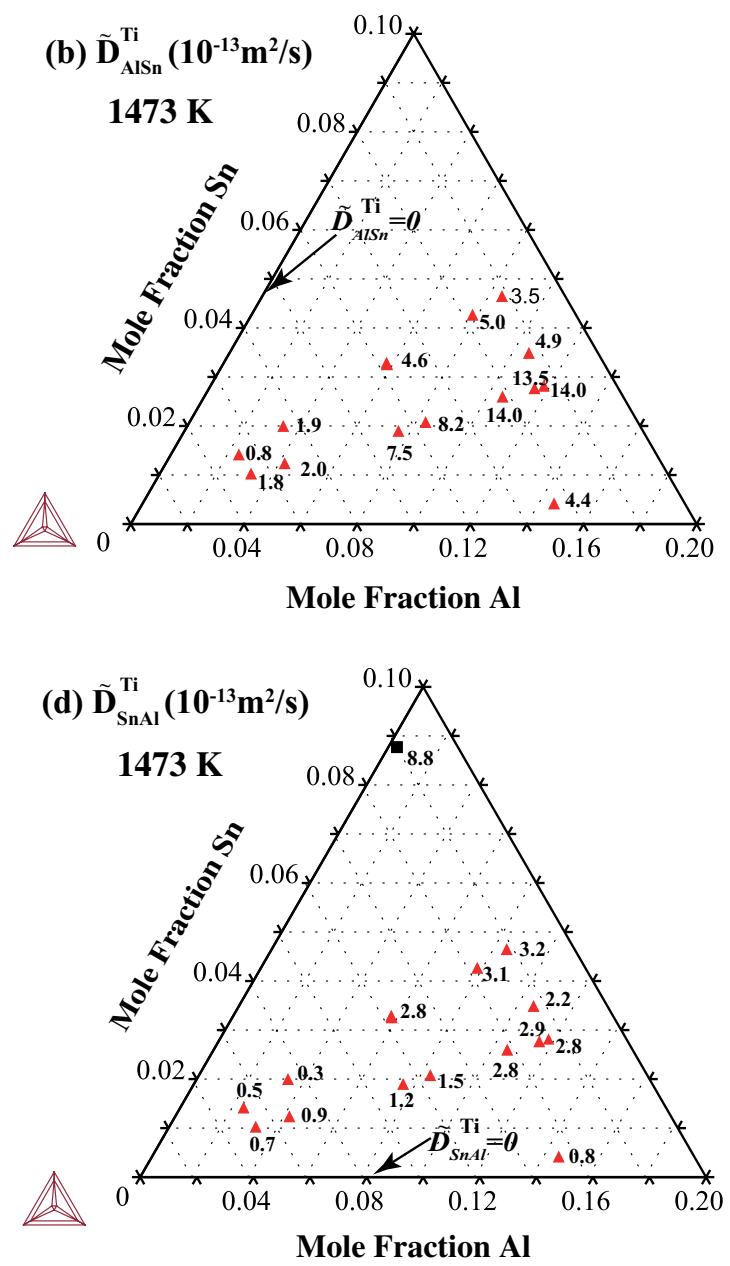

and $\tilde{D}_{\mathrm{Al}(\mathrm{Ti}-\mathrm{Sn})}^{*}$, and the binary interdiffusion coefficients $\tilde{D}_{\mathrm{Ti}-\mathrm{Al}}$ obtained from literature ${ }^{[33]}$ and $\tilde{D}_{\mathrm{Ti}-\mathrm{Sn}}$ by the present work

was illustrated in Fig. 4. A rising linear trend-line was best fit for all four types of interdiffusion data.

The inspection also allows anomalous uphill diffusion to be identified, e.g. Sn diffusion in the couple H6 where Sn is high in content, causing that the Sn profile exhibits a maximum at the marked arrow, i.e. the "Darken-type" couple. ${ }^{[34]}$ In this case, one of the main and one of the cross interdiffusion coefficients at the extreme position can be 

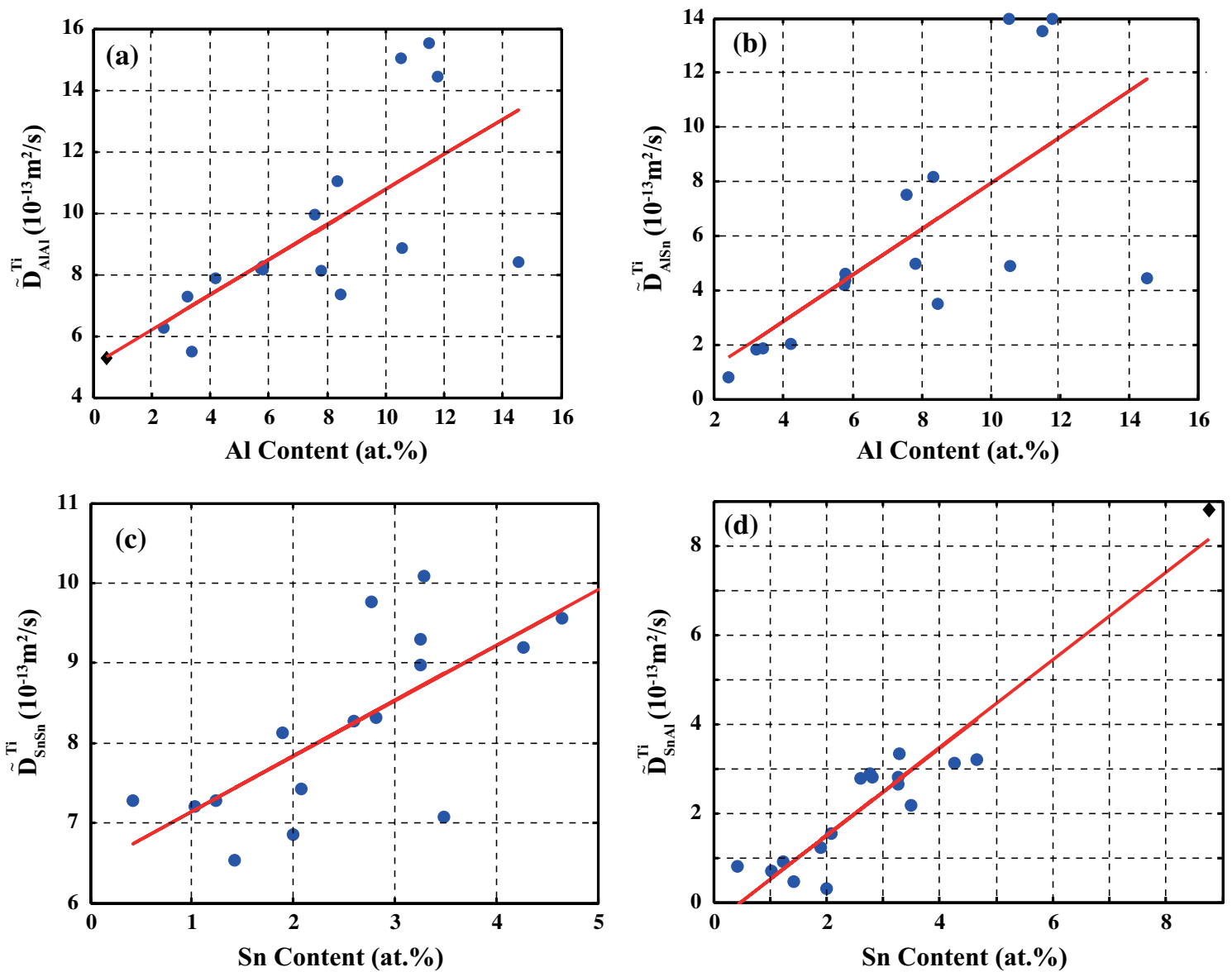

Fig. 4 The variation of ternary interdiffusion coefficients with the compositions. (a) $\tilde{D}_{\mathrm{AlAl}}^{\mathrm{Ti}}$ with $\mathrm{Al}$ and (b) $\tilde{D}_{\mathrm{AlSn}}^{\mathrm{Ti}}$ with $\mathrm{Al}$; (c) $\tilde{D}_{\mathrm{SnSn}}^{\mathrm{Ti}}$ with $\mathrm{Sn}$ and (d) $\tilde{D}_{\text {SnAl }}^{\mathrm{Ti}}$ with $\mathrm{Sn}$

Table 4 Average interdiffusion coefficients in Ti-Al-X $(\mathrm{Co}, \mathrm{Fe}$, $\mathrm{Ni}, \mathrm{Cr}, \mathrm{V}, \mathrm{Mo}$, and $\mathrm{Sn}$ ) ternaries at $1473 \mathrm{~K}$

\begin{tabular}{|c|c|c|c|c|}
\hline & Average $\tilde{D}_{\mathrm{AlAl}}^{\mathrm{Ti}}, \mathrm{m}^{2} / \mathrm{s}$ & Average $\tilde{D}_{\mathrm{XX}}^{\mathrm{Ti}}, \mathrm{m}^{2} / \mathrm{s}$ & Average $\tilde{D}_{\mathrm{AlX}}^{\mathrm{Ti}}, \mathrm{m}^{2} / \mathrm{s}$ & Average $\tilde{D}_{\mathrm{XAl}}^{\mathrm{Ti}}, \mathrm{m}^{2} / \mathrm{s}$ \\
\hline Ti-Al-Co ${ }^{[11]}$ & $1.3 \times 10^{-12}$ & $1.9 \times 10^{-11}$ & $3.3 \times 10^{-13}$ & $2.5 \times 10^{-12}$ \\
\hline Ti-Al-Fe ${ }^{[12]}$ & $1.3 \times 10^{-12}$ & $1.2 \times 10^{-11}$ & $1.8 \times 10^{-13}$ & $1.1 \times 10^{-12}$ \\
\hline Ti-Al-Ni ${ }^{[14]}$ & $1.9 \times 10^{-12}$ & $2.2 \times 10^{-11}$ & $2.8 \times 10^{-13}$ & $-0.5 \times 10^{-12}$ \\
\hline Ti-Al-Cr ${ }^{[9]}$ & $6.8 \times 10^{-13}$ & $4.1 \times 10^{-13}$ & $2.4 \times 10^{-13}$ & $1.4 \times 10^{-13}$ \\
\hline Ti-Al-V ${ }^{[10]}$ & $7.4 \times 10^{-13}$ & $1.6 \times 10^{-12}$ & $2.8 \times 10^{-14}$ & $2.3 \times 10^{-13}$ \\
\hline Ti-Al-Mo ${ }^{[13]}$ & $4.5 \times 10^{-13}$ & $1.5 \times 10^{-13}$ & $7.6 \times 10^{-14}$ & $1.4 \times 10^{-14}$ \\
\hline Ti-Al-Sn & $9.2 \times 10^{-13}$ & $8.2 \times 10^{-13}$ & $5.9 \times 10^{-13}$ & $2.4 \times 10^{-13}$ \\
\hline
\end{tabular}

obtained, for $\mathrm{H} 6$ those are $\tilde{D}_{\mathrm{AlAl}}^{\mathrm{Ti}}\left(5.3 \mathrm{E}-13 \mathrm{~m}^{2} / \mathrm{s}\right)$ and $\tilde{D}_{\mathrm{SnAl}}^{E}\left(8.8 \mathrm{E}-13 \mathrm{~m}^{2} / \mathrm{s}\right)$ at $(0.5$ at. $\% \mathrm{Al}, 8.8$ at. $\% \mathrm{Sn})$.

A systematic comparison of diffusion coefficients of seven $\mathrm{Ti}-\mathrm{Al}-\mathrm{X}$ ( $\mathrm{Co}, \mathrm{Fe}, \mathrm{Ni}, \mathrm{Cr}, \mathrm{V}, \mathrm{Mo}$, and $\mathrm{Sn}$ ) ternaries at $1473 \mathrm{~K}$ was made in Table 4 . The average values of interdiffusion coefficients show that $\mathrm{Co}, \mathrm{Fe}$, and $\mathrm{Ni}$ diffusions are one or two order(s) of magnitude faster than the other four, manifesting themselves with the ultra-fast diffusion anomalies. This is because diffusion of $\mathrm{Co}, \mathrm{Fe}$ and
$\mathrm{Ni}$ in BCC-Ti are predominantly of interstitial nature or a mixed mechanism, ${ }^{[11,12,14,35]}$ and the presence of these alloying elements markedly enhances the $\mathrm{Al}$ diffusion as well. However, the much lower diffusions in Ti-Al- $(\mathrm{Cr}, \mathrm{V}$, Mo, and Sn) occur by the normal vacancy mechanism. Comparing the main interdiffusion terms with the cross ones, the effect of the $\mathrm{Al}$ composition gradient on the diffusion of $\mathrm{Sn}$ is more significant than that of $\mathrm{Co}, \mathrm{Fe}, \mathrm{V}$, and Mo. 


\section{Conclusion}

In brief, the interdiffusion behavior of BCC alloys of Ti-Sn binary and Ti-Al-Sn ternary was investigated at $1473 \mathrm{~K}$ $\left(1200{ }^{\circ} \mathrm{C}\right)$ by the solid-state diffusion couple technique. The inter and impurity diffusion coefficients at $1473 \mathrm{~K}\left(1200{ }^{\circ} \mathrm{C}\right)$ were extracted by the Sauer-Friese, Whittle-Green and Generalized Hall methods, respectively. The interdiffusion coefficient of the Ti-Sn binary was revealed to gradually increase with increasing the Sn content, whereas the main interdiffusion term of the Ti-Al-Sn ternary, either $\tilde{D}_{\mathrm{AlAl}}^{\mathrm{Ti}}$ or $\tilde{D}_{\mathrm{SnSn}}^{\mathrm{Ti}}$, profoundly enhances as the content of diffusing species increases while weakly depends on that of the others. In addition, comparison with Ti-Al-X (Co, Cr, Ni, Fe, Mo, and V) systems, diffusion in Ti-Al-Sn was found to occur by the vacancy mechanism, which is similar to $\mathrm{Cr}, \mathrm{V}$, and Mo.

Acknowledgments This work was supported by the Natural Science Funds of China [Grant No. 51571113], International S\&T Cooperation Program of China (2015DFA51430) and the Joint Project of Industry-University-Research of Jiangsu Province [Grant No: BY2016005]. QW would like to acknowledge the support by the International S\&T Cooperation Program of China (2015DFA51430) and the SICAM Scholarship by Jiangsu National Synergetic Innovation Center for Advanced Materials.

\section{References}

1. R.R. Boyer, An Overview on the Use of Titanium in the Aerospace Industry, Mater. Sci. Eng. A, 1996, 213(1-2), p 103-114

2. P. Wanjara, M. Jahazi, H. Monajati, S. Yue, and J.P. Immarigeon, Hot Working Behavior of Near- $\alpha$ Alloy IMI834, J. Mater. Sci. Eng. A, 2005, 396(1-2), p 50-60

3. A. Madsen and H. Ghonem, Effects of Aging on the Tensile and Fatigue Behavior of the Near- $\alpha$ Ti-1100 at Room Temperature and 593 C, J. Mater. Sci. Eng. A, 1994, 177(1-2), p 63-73

4. J.M. Cai, M.Y. Hao, X.M. Li, and C.X. Cao, Study on Composition Character and Microstructure of BT36 High-temperature Ti Alloy, J. Mater. Eng., 2000, 2, p 10-12

5. Y. Niu and M.Q. Li, Effect of 0.16 wt \% Hydrogen Addition on High-temperature Deformation Behavior of the Ti600 Titanium Alloy, J Mater. Sci. Eng. A, 2009, 513, p 228-232

6. C. Leyans and M. Peters, Titanium and Titanium Alloys: Fundamentals and Applications, Wiley, Hoboken, 2003, p 18-19

7. A.K. Gogia, High-Temperature Titanium Alloys, Def. Sci. J., 2005, 55, p 149-173

8. G. Lütjering and J.C. Williams, Titanium, 2nd ed., Springer, Berlin, 2007, p 23-28

9. T. Takahashi, N. Matsuda, S. Kubo, T. Hino, M. Komatsu, and K. Hisayuki, Interdiffusion in the $\beta$ Solid Solution of Ti-Al-Cr System, J. Jpn. Inst. Met., 2004, 54, p 280-286

10. T. Takahashi, Y. Minamino, and M. Komatsu, Interdiffusion in $\beta$ Phase of Ternary Ti-Al-V System, Mater. Trans., 2008, 49, p 125-132

11. T. Tomoshi, O. Takuya, M. Yoritoshi, and K. Masao, Ternary Diffusion and Thermodynamic Interaction in the $\beta$ solid Solutions of Ti-Al-Co Alloy, J. Jpn. Inst. Met., 2009, 59, p 432-438
12. T. Takahashi and Y. Minamino, Ternary Diffusion and Thermodynamic Interaction in the $\beta$ Solid Solutions of Ti-Al-Fe Alloys at $1423 \mathrm{~K}$, J. Alloys Compd., 2012, 545, p 168-175

13. Y. Chen, B. Tang, G. Xu, C. Wang, H. Kou, J. Li, and Y. Cui, Diffusion Research in BCC Ti-Al-Mo Ternary Alloys, Metall. Mater. Trans. A, 2014, 45, p 1647-1652

14. B. Gao, Y. Gu, Q. Wu, Y. Guo, and Y. Cui, Diffusion Research in BCC Ti-Al-Ni Ternary Alloys, J. Phase Equilib. Diffus., 2017, 38, p 502-508

15. J. Askill and G.B. Gibbs, Tracer Diffusion in $\beta$-Titanium, Phys. Status Solidi., 1965, 11, p 557-565

16. M.S. Jackson and D. Lazarus, Isotope Effect for Diffusion of Tin in beta-Titanium, Phys. Rev. B, 1977, 15(10), p 4644-4656

17. G. Neumann, V. Tölle, and C. Tuijn, On the Impurity Diffusion in $\beta$-Ti, Phys. B, 2001, 296, p 334-341

18. Yoshiaki Iijima, Sung-Yul Lee, and Ken-Ichi Hirano, Diffusion of Silicon, Germanium and Tin in $\beta$-titanium, Philos. Mag. A, 1993, 68, p 901-914

19. H. Araki, T. Yamane, Y. Minamino, S. Saji, Y. Fujiishi, and Y. Miyamoto, Effect of Pressure on the Anomalous Diffusion of Tin in beta-Titanium, Mater. Trans., 1993, 34, p 763-770

20. C.P. Wang, Y.S. Luo, L.U. Yong, J.J. Han, Y.H. Guo, Y.H. Liu, and X.J. Liu, Measurement of Interdiffusivities and Calculation of Kinetics in bcc Ti-Sn and Ti-Ni Binary Systems, J. Xiamen Univ., 2017, 56, p 25-32

21. I. Ohnuma, Y. Fujita, H. Mitsui, K. Ishikawa, R. Kainuma, and K. Ishida, Phase Equilibria in the Ti-Al Binary System, Acta Mater., 2000, 48, p 3113-3123

22. T.B. Massalski, J.L. Murray, L.H. Bennett, and H. Baker, Binary Alloy Phase Diagrams, ASM, Materials Park, 1990, p 1482-1495

23. I.I. Kornilov and T.T. Nartova, Phase Diagram of the Ti-Al-Sn System, Dokl. Akad. Nauk SSSR, 1960, 131(4), p 837-839

24. F. Sauer and V. Freise, Diffusion in Binaren Gemischen mit Volumenanderung, Z. Elektrochem., 1962, 66, p 353-363, in German

25. T.O. Ziebold and R.E. Ogilvie, Ternary Diffusion in CopperSilver-Gold Alloys, Trans. Met. Soc., 1967, 239, p 942-953

26. D.P. Whittle and A. Green, The Measurement of Diffusion Coefficients in Ternary Systems, Scr. Metall., 1974, 8, p 883-884

27. L.D. Hall, An Analytical Method of Calculating Variable Diffusion Coefficients, J. Chem. Phys., 1953, 21, p 87-89

28. T. Tomoshi, K. Michitomo, M. Yoritoshi, and Y. Toshimi, Interdiffusion in a Solid Solutions of Cu-Al-Zn System, Trans. Jpn. Inst. Met., 1985, 26, p 462-472

29. A.G. Nikitin, S.V. Spichak, Y.S. Vedula, and A.G. Naumovets, Symmetries and Modelling Functions for Diffusion Processes, $J$. Phys. D, 2009, 42, p 055301

30. P. Shewmon, Diffusion in Solids, 2nd ed., The Minerals, Metals \& Materials Society, 1989

31. J.S. Kirkaldy, D. Weichert, and Z.U. Haq, Diffusion in Multicomponent Metallic Systems: VI. Some Thermodynamic Properties of the D Matrix and the Corresponding Solutions of the Diffusion Equations, Can. J. Phys., 1963, 41, p 2166-2173

32. F.O. Shuck and H.L. Toor, Diffusion in the Three Component Liquid System Methyl Alcohol-n-Propyl Alcohol-Isobutyl Alcohol, J. Phys. Chem., 1963, 67, p 540-545

33. S.Y. Lee, O. Taguch, and Y. Lijima, Diffusion of Aluminum in $\beta$ Titanium, Mater. Trans., 2010, 51, p 1809-1813

34. M.A. Dayananda, Diffusion in Multicomponent Alloys: Challenges and Problems, Defect Diffus. Forum, 1992, 83, p 73-86

35. G.M. Hood and R.J. Schultz, Ultra-fast solute diffusion in $\alpha$-Ti and $\alpha-Z r$, Philos. Mag., 1972, 26, p 329-336 